\title{
Wheat gluten hydrolysate affects race performance in the triathlon
}

\author{
NATSUE KOIKAWA $^{1}$, EMI AOKI ${ }^{1}$, YOSHIO SUZUKI ${ }^{2}$, KEISHOKU SAKURABA $^{2}$, ISAO NAGAOKA ${ }^{3}$, \\ KAZUHIRO AOKI ${ }^{1}$, YUKI SHIMMURA ${ }^{4}$ and KEISUKE SAWAKI ${ }^{1}$ \\ ${ }^{1}$ School of Health and Sports Science; ${ }^{2}$ Graduate School of Health and Sports Science, Juntendo University, Inzai, \\ Chiba 270-1695; ${ }^{3}$ Department of Host Defense and Biochemical Research, Graduate School of Medicine, \\ Juntendo University, Bunkyo, Tokyo 113-8421; ${ }^{4}$ Nisshin Pharma Inc., Chiyoda, Tokyo 101-8441, Japan
}

Received March 5, 2013; Accepted May 9, 2013

DOI: $10.3892 /$ br.2013.105

\begin{abstract}
Wheat gluten hydrolysate (WGH) is a food ingredient, prepared by partial enzymatic digestion of wheat gluten, which has been reported to suppress exercise-induced elevation of serum creatinine kinase (CK) activity. However, its effects on athletic performance have not yet been elucidated. This is the presentation of an experiment performed on five female college triathletes who completed an Olympic distance triathlon with or without ingestion of $21 \mathrm{~g}$ of WGH during the cycling leg. The experiment was performed in a crossover double-blind manner. The race time of the running leg and thus the total race time was significantly shorter when WGH was ingested. However, serum CK levels exhibited no apparent differences between the two WGH or placebo groups.
\end{abstract}

\section{Introduction}

Wheat gluten hydrolysate (WGH) is a food ingredient prepared by partial enzymatic digestion of wheat gluten, which contains a significant amount of glutamine. Glutamine is the most abundant amino acid in the serum and comprises $\sim 60 \%$ of the free amino acid content of skeletal muscle. It serves as an energy source for immune cells and intestinal mucosal cells and as a precursor of glucose (1).

WGH has been reported to inhibit the elevation of serum creatine kinase $(\mathrm{CK})$ induced by long-distance running $(2,3)$, $100-\mathrm{km}$ race walking (4), soccer (5) and resistance training (6). In resistance training, the elevation of serum $\mathrm{CK}$ at the end of exercise was inhibited by ingestion of WGH prior to exercising (6) and in a $100-\mathrm{km}$ race walking serum CK elevation was inhibited by ingestion of WGH during the race (4).

Correspondence to: Natsue Koikawa, Department of Sports Science, School of Health and Sports Science, Juntendo University, 1-1 Hiraga-gakuendai, Inzai, Chiba 270-1695, Japan

E-mail: koikawa@sakura.juntendo.ac.jp

Key words: triathlon, wheat gluten hydrolysate, inflammation
$\mathrm{CK}$ is released from skeletal muscle into the serum as a result of the muscle damage caused by exercise and also by the inflammatory response accompanying exercise (7). Therefore, with the same amount of exercise loading, the differences in the elevation of serum CK may be attributed to differences in the inflammatory response. According to a previous study by Koikawa et al (3), post-exercise WBC counts were correlated with serum CK levels at $24 \mathrm{~h}$. However, this correlation was not observed in the WGH group. Therefore, it was hypothesized that WGH suppressed tissue inflammation associated with exercise.

When exercise is performed for a long period of time, mechanical stress and inflammatory response accumulate, leading to muscle damage. Thus, performance is expected to increase if muscle damage is minimized. It was previously reported that when WGH was ingested every $10 \mathrm{~km}$ during a $100-\mathrm{km}$ race walking, post-race elevation of serum CK levels was inhibited and race times were shorter compared to those in the group without WGH ingestion (4). However, considering the small sample size, the fact that there was a one-year interval between races and the differences between the racing environment of different events (e.g., the weather may affect race walking in a $100-\mathrm{km}$ ultramarathon which is held outdoors), the effect of WGH is considered to be anecdotal.

A triathlon is a multiple-stage competition involving the completion of three continuous and sequential endurance events: swimming, cycling and running. In general, serum CK activity was only mildly increased after exercise lasting $\leq 60 \mathrm{~min}(8)$. However, a previous study by van Rensburg et al (9) reported significant elevations following a triathlon race and concluded that the physiological demand of the triathlon exceeds that of other comparable endurance events.

This study aimed to determine the effect of WGH ingestion on triathlon race performance and muscle damage.

\section{Materials and methods}

Subjects. Five female triathletes belonging to a college triathlon team participated in this study. Their characteristics are shown in Table I. The athletes were provided a thorough explanation of the objectives, methods and ethical considerations of the study and provided written informed consent prior to their participation. 


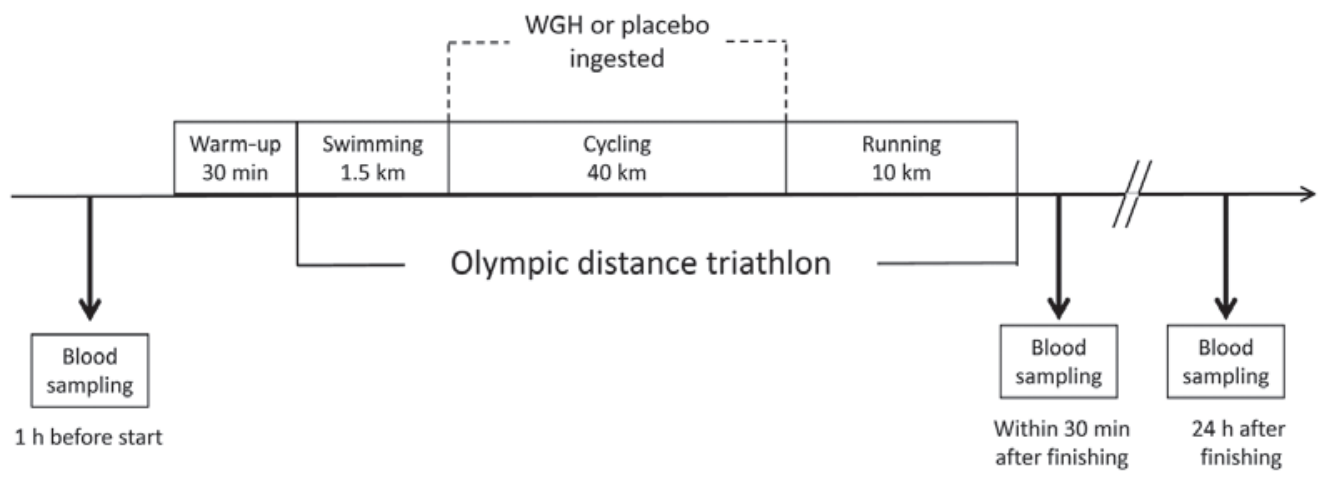

Figure 1. Experimental protocol.

Table I. Subject characteristics.

\begin{tabular}{|c|c|c|c|c|c|c|c|c|c|}
\hline \multirow[b]{2}{*}{ Subject } & \multirow{2}{*}{$\begin{array}{c}\text { Age } \\
(\mathrm{y})\end{array}$} & \multirow{2}{*}{$\begin{array}{l}\text { Height } \\
(\mathrm{cm})\end{array}$} & \multirow{2}{*}{$\begin{array}{l}\text { Weight } \\
(\mathrm{kg})\end{array}$} & \multirow{2}{*}{$\begin{array}{c}\text { Body fat } \\
(\%)\end{array}$} & \multicolumn{4}{|c|}{ Personal best in Olympic distance race ${ }^{a}$} & \multirow[b]{2}{*}{ Race } \\
\hline & & & & & Swimming & Cycling & Running & Total & \\
\hline A & 21 & 157.5 & 51.9 & 17.2 & $24^{\prime} 15^{\prime \prime}$ & $1: 10^{\prime} 46^{\prime \prime}$ & $45^{\prime} 52^{\prime \prime}$ & $2: 20 ' 53^{\prime \prime}$ & 8th, Kanto College Student's Championship 2010 \\
\hline B & 21 & 161.0 & 54.9 & 22.1 & $25^{\prime} 30^{\prime \prime}$ & 1:09'09" & $47^{\prime} 07^{\prime \prime}$ & $2: 25 ' 04^{\prime \prime}$ & Watarase Spring Triathlon 2010 \\
\hline $\mathrm{C}$ & 20 & 166.5 & 58.8 & 20.1 & $25^{\prime} 58^{\prime \prime}$ & $1: 12^{\prime} 57^{\prime \prime}$ & $45^{\prime} 57^{\prime \prime}$ & $2: 268^{\prime \prime}$ & 23rd, Kanto College Student's Championship 2010 \\
\hline $\mathrm{D}$ & 19 & 155.5 & 46.6 & 19.7 & $287^{\prime} 17^{\prime \prime}$ & $1: 14^{\prime} 12^{\prime \prime}$ & $40^{\prime} 48^{\prime \prime}$ & $2: 23^{\prime} 17^{\prime \prime}$ & 15th, Kanto College Student's Championship 2010 \\
\hline $\mathrm{E}$ & 18 & 163.0 & 59.7 & 24.3 & $31^{\prime} 35^{\prime \prime}$ & $1: 11^{\prime} 52^{\prime \prime}$ & $45^{\prime} 30^{\prime \prime}$ & $2: 36 ' 31^{\prime \prime}$ & 37th, Kanto College Student's Championship 2010 \\
\hline
\end{tabular}

aTime: h:min'sec"; y, years.

Study design. The present was a double-blind crossover study with a two-week interval. The experiment involved a triathlon race, including blood monitoring, dietary survey and a self-administered questionnaire for ratings of perceived exertion (Fig. 1). The study was conducted during July and August, 2010. The subjects completed an Olympic distance triathlon, comprising a $1.5-\mathrm{km}$ swimming leg, a $40-\mathrm{km}$ cycling leg and a $10-\mathrm{km}$ running leg. The subjects ingested WGH or placebo during the cycling leg and the order was randomly assigned. During the race, the subjects were allowed to drink water freely. Venous blood was collected $1 \mathrm{~h}$ prior to, on completion of and $24 \mathrm{~h}$ following the triathlon race. Serum total protein (TP), lactate dehydrogenase (LDH), creatine kinase (CK), aspartate aminotransferase (AST), alanine transaminase (ALT), creatinine (CRE) and white blood cell count (WBC) were measured in the laboratory of SRL Inc. (Tokyo, Japan).

Subjects refrained from taking dietary supplements for the week preceding the race and were prohibited from training one day prior to the race.

This study was reviewed and approved by the Ethics Committee of the Juntendo University School of Health and Sports Science.

Study drink. WGH was provided as a drink prepared using a granulated powder containing WGH. Other ingredients included anhydrous glucose, anhydrous citric acid, a sweetener (sucralose), lemon fragrance and a thickener (pullulan). The placebo drink contained a water soluble fiber, poly-
Table II. Composition of study drink.

\begin{tabular}{llc}
\hline Supplement & \multicolumn{1}{c}{ Ingredient } & Content $(\mathrm{g} / 300 \mathrm{ml})$ \\
\hline Placebo & Polydextrose & 21 \\
& Anhydrous glucose & 7 \\
& Anhydrous citric acid & 3.15 \\
& Sucralose (sweetener) & 0.056 \\
& Lemon fragrance & 0.294 \\
& Pullulan (thickener) & 0.4725 \\
WGH & Wheat gluten hydrolysate & 21 \\
& Anhydrous glucose & 7 \\
& Anhydrous citric acid & 3.15 \\
& Sucralose (sweetener) & 0.056 \\
& Lemon flavor & 0.294 \\
& Pullulan (thickener) & 0.4725 \\
\hline
\end{tabular}

WGH, wheat gluten hydrolysate.

dextrose, instead of WGH, with the other ingredients being identical. Granulated powders were prepared by Nisshin Pharma Inc. (Tokyo, Japan). Detailed compositions are listed in Table II. The study drink was dissolved in $300 \mathrm{ml}$ of water and provided to the subjects, who consumed the drink during the cycling leg. 
Table III. Race data for the triathlon.

\begin{tabular}{|c|c|c|c|c|}
\hline \multirow[b]{2}{*}{ Subject } & \multicolumn{4}{|c|}{ Race times } \\
\hline & Swimming & Cycling & Running & Total \\
\hline \multicolumn{5}{|l|}{ Placebo } \\
\hline A & 23'13'01 & $1: 12^{\prime} 25^{\prime \prime 29}$ & 51'58'36 & $2: 29^{\prime} 10^{\prime \prime} 49$ \\
\hline B & $23^{\prime} 53 " 62$ & 1:10'56"78 & $52^{\prime} 00^{\prime \prime} 69$ & $2: 28^{\prime} 14^{\prime \prime} 79$ \\
\hline $\mathrm{C}$ & $24^{\prime} 53^{\prime \prime 27}$ & 1:18'49"57 & 54'28"69 & 2:39'40"31 \\
\hline $\mathrm{D}$ & 26'19"91 & 1:16'02'88 & 41'33"15 & $2: 25^{\prime} 26^{\prime \prime} 95$ \\
\hline $\mathrm{E}$ & 30'30'31 & 1:11'05"66 & 48'36"82 & $2: 31^{\prime} 42^{\prime \prime} 15$ \\
\hline Mean & $25^{\prime} 26^{\prime \prime} 78$ & 1:13'52'04 & 49'26"93 & $2: 30^{\prime} 50^{\prime \prime} 94$ \\
\hline SD & 2'54"72 & $3^{\prime} 27^{\prime \prime} 10$ & $5^{\prime} 7 " 08$ & 5'24'92 \\
\hline \multicolumn{5}{|l|}{ WGH } \\
\hline A & $23^{\prime} 33^{\prime \prime} 62$ & 1:10'19"80 & 48'39"24 & $2: 23^{\prime} 48^{\prime \prime} 83$ \\
\hline B & 23'33'84 & 1:10'19"39 & $49 ' 07^{\prime \prime} 87$ & $2: 24^{\prime} 20^{\prime \prime} 62$ \\
\hline $\mathrm{C}$ & 24'59"36 & 1:16'53"61 & 50'29"92 & $2: 33^{\prime} 49^{\prime \prime} 01$ \\
\hline $\mathrm{D}$ & $25^{\prime} 45^{\prime \prime} 55$ & 1:17'10'25 & 41'10"03 & $2: 25^{\prime} 21^{\prime \prime} 90$ \\
\hline $\mathrm{E}$ & $30 ' 26$ '23 & 1:09'16"67 & 47'36"98 & $2: 28^{\prime} 50^{\prime \prime} 30$ \\
\hline Mean & $25^{\prime} 20^{\prime \prime} 03$ & 1:12'47"94 & 47'15"54 & 2:27'14"13 \\
\hline SD & $2^{\prime} 47^{\prime \prime} 45$ & 3'53"35 & 3'39"57 & 4'10"01 \\
\hline P-value ${ }^{a}$ & 0.613 & 0.153 & 0.039 & 0.025 \\
\hline
\end{tabular}

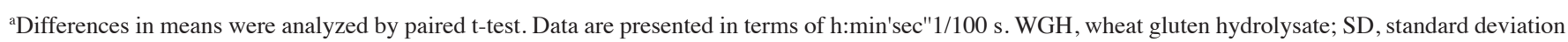

Table IV. Blood parameters.

\begin{tabular}{|c|c|c|c|}
\hline Parameter & Pre-race & Goal & Post-race $(24 \mathrm{~h})$ \\
\hline \multicolumn{4}{|l|}{ Placebo } \\
\hline $\mathrm{TP}(\mathrm{g} / \mathrm{dl})$ & $7.0 \pm 0.2$ & $7.6 \pm 0.6^{\mathrm{a}}$ & $7.2 \pm 0.5$ \\
\hline TG (mg/dl) & $63 \pm 37$ & $41 \pm 7$ & $41 \pm 22$ \\
\hline CK (U/l) & $146.6 \pm 59.4$ & $190.2 \pm 69.7^{\mathrm{b}}$ & $197.8 \pm 64.9^{\mathrm{b}}$ \\
\hline $\operatorname{ALT}(\mathrm{U} / \mathrm{l})$ & $22.4 \pm 6.8$ & $27.0 \pm 9.3^{\mathrm{a}}$ & $25.2 \pm 8.73$ \\
\hline $\operatorname{AST}(\mathrm{U} / \mathrm{l})$ & $27.8 \pm 8.5$ & $36.4 \pm 10.6^{\mathrm{b}}$ & $32.6 \pm 7.5$ \\
\hline LDH (U/l) & $224.0 \pm 22.4^{\mathrm{e}}$ & $279.6 \pm 23.9^{\mathrm{b}}$ & $244.2 \pm 17.2^{\mathrm{c}}$ \\
\hline CRE (mg/dl) & $0.68 \pm 0.05$ & $1.16 \pm 0.17^{\mathrm{b}}$ & $0.73 \pm 0.05^{\mathrm{d}}$ \\
\hline $\mathrm{Fe}(\mu \mathrm{g} / \mathrm{dl})$ & $94 \pm 43$ & $115 \pm 40$ & $99 \pm 19$ \\
\hline $\mathrm{WBC}(/ \mu 1)$ & $5,100 \pm 1,387$ & $9,520 \pm 2,983^{b}$ & $5,740 \pm 984^{\mathrm{d}}$ \\
\hline \multicolumn{4}{|l|}{ WGH } \\
\hline $\mathrm{TP}(\mathrm{g} / \mathrm{dl})$ & $7.0 \pm 0.3$ & $7.7 \pm 0.5^{\mathrm{b}}$ & $7.2 \pm 0.3^{\mathrm{c}}$ \\
\hline TG (mg/dl) & $61 \pm 22$ & $50 \pm 13$ & $50 \pm 27$ \\
\hline CK (U/l) & $154.0 \pm 109.7$ & $200.6 \pm 129.4^{b}$ & $190.4 \pm 116.4^{a}$ \\
\hline $\operatorname{ALT}(\mathrm{U} / \mathrm{l})$ & $16.6 \pm 3.2$ & $22.6 \pm 7.8$ & $23.0 \pm 8.54$ \\
\hline AST (U/l) & $24.6 \pm 6.6$ & $36.0 \pm 17.9$ & $33.2 \pm 10.5$ \\
\hline LDH (U/l) & $217.2 \pm 22.5^{\mathrm{e}}$ & $284.0 \pm 37.3^{\mathrm{b}}$ & $241.8 \pm 23.5^{\mathrm{a}, \mathrm{d}}$ \\
\hline CRE (U/l) & $0.67 \pm 0.08$ & $1.12 \pm 0.15^{\mathrm{b}}$ & $0.67 \pm 0.08^{\mathrm{d}}$ \\
\hline $\mathrm{Fe}(\mu \mathrm{g} / \mathrm{dl})$ & $90 \pm 34$ & $133 \pm 46^{b}$ & $89 \pm 30^{\mathrm{d}}$ \\
\hline $\mathrm{WBC}(/ \mu 1)$ & $4,480 \pm 683$ & $8,140 \pm 1,288^{b}$ & $5,840 \pm 2,233^{\mathrm{c}}$ \\
\hline
\end{tabular}

${ }^{a} \mathrm{P}<0.05$ and ${ }^{\mathrm{b}} \mathrm{P}<0.01$ vs. pre-race, ${ }^{\mathrm{C}} \mathrm{P}<0.05$ and ${ }^{\mathrm{d}} \mathrm{P}<0.01$ vs. post-race and ${ }^{\mathrm{e}} \mathrm{P}<0.05$ for $\mathrm{WGH}$ vs. placebo. TP, serum total protein; TG, triglyceride; $\mathrm{CK}$, creatine kinase; ALT, alanine transaminase; AST, aspartate aminotransferase; LDH, lactate dehydrogenase; CRE, creatinine; Fe, iron; WBC, white blood cell count; WGH, wheat gluten hydrolysate. 
Statistical analyses. Race times and data are presented as h:min's"1/100 sec and means \pm standard deviation (SD), respectively. Changes in serum parameters were assessed using two-way analysis of variance followed by the Tukey-Kramer test. Comparison of the two groups was performed by the paired t-test. $\mathrm{P}<0.05$ was considered to indicate a stitistically significant difference.

\section{Results}

Race performance of the subjects. The race performance of the subjects ingesting WGH was as follows: swimming leg,

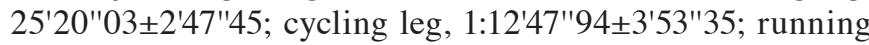

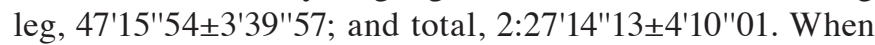
placebo was ingested, race times were as follows: swim-

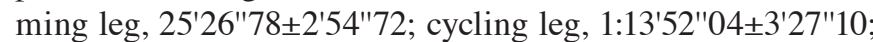
running leg, 49'26"93 $\pm 5^{\prime} 7$ " $^{\prime} 08$; and total 2:30'50"94 $\pm 5^{\prime} 24^{\prime \prime} 92$. It was observed that running leg and total times were shorter $(\mathrm{P}<0.05)$ with WGH ingestion compared to placebo (Table III).

Blood parameters of the two groups. Blood parameters are shown in Table IV. During the race, serum CK increased to $200.6 \pm 129.4(\mathrm{WGH})$ and $190.2 \pm 69.7 \mathrm{U} / 1$ (placebo) from $154.0 \pm 109.7$ and $146.6 \pm 59.4 \mathrm{U} / 1$, respectively $(\mathrm{P}<0.01)$. Twenty-four hours later, serum CK was furtherelevated $(\mathrm{P}<0.05)$, reaching 190.4 $\pm 116.4(\mathrm{WGH})$ and 197.8 $\pm 64.9 \mathrm{U} / 1$ (placebo) compared to the pre-race levels. Although there were no significant differences between the WGH and placebo groups, post-exercise mean $\mathrm{CK}$ had decreased after $24 \mathrm{~h}$ in the WGH ingestion group, whereas it remained elevated in the placebo group.

The kinetics of serum ALT were similar to those of CK. Twenty-four hours after exercise, serum ALT with WGH ingestion was $23.0 \pm 8.54 \mathrm{U} / 1$, which was lower compared to that with placebo ingestion, which was $25.2 \pm 8.73 \mathrm{U} / 1$, although the difference was not significant $(\mathrm{P}=0.051)$.

In the WGH group, LDH was $217.2 \pm 22.5 \mathrm{U} / 1$ pre-race, $284.0 \pm 37.3 \mathrm{U} / 1$ post-race and $241.8 \pm 23.5 \mathrm{U} / 1$ at $24 \mathrm{~h}$ after the race. In the placebo group, $\mathrm{LDH}$ was $224.0 \pm 22.4 \mathrm{U} / 1$ pre-race, $279.6 \pm 23.9 \mathrm{U} / 1$ post-race and $244.2 \pm 17.2 \mathrm{U} / 1$ at $24 \mathrm{~h}$ after the race. In both groups, there was a significant elevation in $\mathrm{LDH}$ levels $(\mathrm{P}<0.01)$ from pre- to post-race and at $24 \mathrm{~h}$ after the race, LDH had significantly decreased compared to its post-race levels $(\mathrm{P}<0.01)$. However, at $24 \mathrm{~h}$ after the race, its levels remained significantly higher compared to the pre-race levels $(\mathrm{P}<0.01)$. No significant differences were observed between the two groups.

\section{Discussion}

In this experiment, all the subjects initiated ingestion of the test drink immediately after switching to cycling after swimming. There were no differences between the WGH and placebo groups as regards swimming and cycling times, however, running times were shorter in the WGH compared to the placebo group and total race times were also shorter in the WGH group. Since the test drink was ingested during the cycling leg of the triathlon race, the difference in running times may be attributed to WGH.
Enzyme release from muscle tissue into the serum indicates muscle damage (8). Previous studies reported CK and LDH elevations at the end of a triathlon race, with the levels remaining high at six days after the completion of the race (swimming leg, $3.9 \mathrm{~km}$; cycling leg, $180.2 \mathrm{~km}$; and running leg, $42.2 \mathrm{~km})(10,11)$. Serum CK and LDH levels were also reported to increase after a middle-distance triathlon (swimming leg, $2.0 \mathrm{~km}$; cycling leg, $90.0 \mathrm{~km}$; and running leg, $21.0 \mathrm{~km}$ ), with $\mathrm{CK}$ reaching a peak at $24 \mathrm{~h}$ after the race (12). In the present study, $\mathrm{CK}$ kinetics with placebo ingestion continued to increase for $24 \mathrm{~h}$ after the race, which was consistent with the findings of previous studies (10-12). By contrast, mean $\mathrm{CK}$ decreased in the $24 \mathrm{~h}$ after the completion of the race. Findings of a previous study by Aoki et al (5) reported the same discrepancy in $\mathrm{CK}$ kinetics after a mini-soccer game: with post-exercise ingestion of placebo, mean $\mathrm{CK}$ at $24 \mathrm{~h}$ had increased, whereas it had decreased with WGH ingestion. Therefore, WGH ingestion during the cycling leg may have suppressed post-exercise CK elevation, as previously reported (2-5). However, the difference in post-exercise transition was not significant and could not be confirmed in this study.

Our hypothesis was that WGH ingestion during the cycling leg would suppress the inflammatory muscle damage during the subsequent running leg and improve running times. In this respect, subjects achieved shorter running times when administered WGH compared to placebo, whereas post-race serum CK activity did not differ between the two groups. The ergogenic effects of WGH on race performance are of interest. However, due to the limited sample size and lack of sound evidence supporting the underlying mechanism, additional investigations are required to elucidate the efficacy of WGH in improving athletic performance.

\section{Acknowledgements}

This study was partially funded by Nisshin Pharma Inc. (Tokyo, Japan), which is one of the manufacturers of WGH.

\section{References}

1. Young VR and Ajami AM: Glutamine: the emperor or his clothes? J Nutr 131 (9 Suppl): S2449-S2459, 2001.

2. Sawaki K, Takaoka I, Sakuraba K and Suzuki Y: Effects of distance running and subsequent intake of glutamine rich peptide on biomedical parameters of male Japanese athletes. Nutr Res 24: 59-71, 2004.

3. Koikawa N, Nakamura A, Ngaoka I, Aoki K, Sawaki K and Suzuki Y: Delayed-onset muscle injury and its modification by wheat gluten hydrolysate. Nutrition 25: 493-498, 2009.

4. Koikawa N, Suzuki Y, Matsuo A, Aoki K, Matsuoka Y, Nagaoka I and Sakawa K: Effect of WGH ingestion on muscle damage accompanying a 100-km walk. J Jpn Soc Clin Sports Med (The 19th Ann Meeting of Jap Soc Clin Sports Med) 16: S167, 2008 (In Japanese).

5. Aoki K, Kohmura Y, Suzuki Y, Koikawa N, Yoshimura M, Aoba Y, Fukushi N, Sakuraba K, Nagaoka I and Sawaki K: Post-training consumption of wheat gluten hydrolysate suppresses the delayed onset of muscle injury in soccer players. Exp Ther Med 3: 969-972, 2012.

6. Takanashi Y, Suzuki Y, Aoki K, Koikawa N, Shinmura Y, Sakuraba K and Kaneko K: Effect of an intake of WGH on strength training for a thrower's. J Jpn Soc Clin Sports Med 20: 66-71, 2012 (In Japanese).

7. Armstrong RB: Mechanisms of exercise-induced delayed onset muscular soreness: a brief review. Med Sci Sports Exerc 16: $529-538,1984$. 
8. Noakes TD: Effect of exercise on serum enzyme activities in humans. Sports Med 4: 245-267, 1987.

9. van Rensburg JP, Kielblock AJ and van der Linde A: Physiologic and biochemical changes during a triathlon competition. Int $\mathrm{J}$ Sports Med 7: 30-35, 1986.

10. Farber HW, Schaefer EJ, Franey R, Grimaldi R and Hill NS The endurance triathlon: metabolic changes after each event and during recovery. Med Sci Sports Exerc 23: 959-965, 1991.
11. Holly RG, Barnard RJ, Rosenthal M, Applegate E and Pritikin N: Triathlete characterization and response to prolonged strenuous competition. Med Sci Sports Exerc 18: 123-127, 1986

12. Esaki K, Miyagami H and En Y: Effects of middle-distance triathlon race on serum biochemical parameters. Jpn J Phys Fitness Sports Med 45: 429-439, 1996. 